\title{
STUDY ON CREEP PROPERTIES OF CONCRETE
}

\section{COMBINED WITH RECYCLED AGGREGATE AND FLY}

\author{
ASH \\ $\underline{\text { Shunsuke Hayashi }}{ }^{1}$, Koji Takasu $^{2}$, Hidehiro Koyamada ${ }^{2}$, Hiroki Suyama ${ }^{3}$ \\ ${ }^{1}$ 1-1 Hibikino Wakamatsu-ku Kitakyushu, Fukuoka, 808-0135, Japan, \\ z8mbb020@eng.kitakyu-u.ac.jp, Graduate School, The Univ. of Kitakyushu. \\ ${ }^{2}$ Prof., Dr. Eng., The Univ. of Kitakyushu. \\ ${ }^{3}$ Assoc. Prof., Dr. Eng., The Univ. of Kitakyushu.
}

\begin{abstract}
In the present the study, recycled aggregate attains the practical level as a recycled material by investigating the creep properties of the recycled concrete and recycled concrete containing fly ash and to investigate whether the creep prediction equation of the past research can be applied. In the case of calculating the predicted value using the Architectural Institute of Japan (AIJ) equation, it was confirmed that by using not only the correction factor of recycled concrete but also the correction factor considering the influence of admixture, it is possible to predict creep more accurately. It was confirmed that the correction factor proposed in the prediction formula is greatly influenced by the water absorption in both concrete mixes with and without fly ash.
\end{abstract}

Keywords: Recycled aggregate, creep, concrete, fly ash, water absorption.

\section{INTRODUCTION}

Ecological awareness is increasing throughout society, including in the building sector. It has been estimated that construction waste accounts for approximately $20 \%$ of total industrial waste emissions. In Japan, massive quantities of concrete scraps will also be generated in the future owing to the demolition of large numbers of buildings constructed during the country's period of high economic growth, and more extensive use of recycled aggregate is expected. However, there have been very few reports ${ }^{1), 2)}$ on the creep properties of concrete prepared using recycled aggregate, which is a 
problem in terms of ensuring the durability of these materials.

In this study, we evaluated the creep properties of recycled aggregate concrete specimens containing fly ash. Furthermore, we compared the predicted creep properties of these concretes calculated using a previously reported equation with the experimentally measured values.

\section{EXPERIMENTAL METHODS}

Table 1 summarizes the materials used in this study. We used ordinary Portland cement, recycled fine aggregates of two different qualities ${ }^{3)}$ (M class prescribed in JIS A 5022 and L class prescribed in JIS A 5023), and recycled coarse aggregates of two different qualities (M class prescribed in JIS A 5022 and L class prescribed in JIS A 5023). For comparison, we used sea sand as fine aggregate and crushed stone as coarse aggregate. The fly ash was equivalent to class II prescribed in JIS A 6201 ("Fly Ash for Concrete").

Table 1. Materials

\begin{tabular}{|c|c|c|c|}
\hline & Kind & Property & Symbol \\
\hline Cement & Ordinary portland cement & Density $3.16\left[\mathrm{~g} / \mathrm{cm}^{3}\right]$ & $\overline{\mathrm{C}}$ \\
\hline Water & Tap water & - & $\mathrm{W}$ \\
\hline \multirow{14}{*}{ Fine Aggregate } & \multirow{4}{*}{ Sea sand } & Absolute dry density:2.59[g/ $\left.\mathrm{cm}^{3}\right]$ & \multirow{4}{*}{ NS } \\
\hline & & Water absorption: $0.76 \%$ & \\
\hline & & Fineness modulus:2.4 & \\
\hline & & Solid content: $61.2 \%$ & \\
\hline & \multirow{5}{*}{$\begin{array}{l}\text { M class Recycled } \\
\text { fine aggregate }\end{array}$} & Absolute dry density: $2.28\left[\mathrm{~g} / \mathrm{cm}^{3}\right]$ & \multirow{5}{*}{ MS } \\
\hline & & Water absorption:5.93\% & \\
\hline & & Fineness modulus:2.6 & \\
\hline & & Solid content:56.3\% & \\
\hline & & Adhesive mortar ratio: $21.7 \%$ & \\
\hline & \multirow{5}{*}{$\begin{array}{l}\text { L class Recycled } \\
\text { fine aggregate }\end{array}$} & Absolute dry density: $2.01\left[\mathrm{~g} / \mathrm{cm}^{3}\right]$ & \multirow{5}{*}{$\mathrm{LS}$} \\
\hline & & Water absorption: $12.4 \%$ & \\
\hline & & Fineness modulus:2.2 & \\
\hline & & Solid content:52.5\% & \\
\hline & & Adhesive mortar ratio: $13.98 \%$ & \\
\hline \multirow{14}{*}{ Coarse Aggregate } & \multirow{4}{*}{ Crushed stone } & Absolute dry density: $2.69\left[\mathrm{~g} / \mathrm{cm}^{3}\right]$ & \multirow{4}{*}{ NG } \\
\hline & & Water absorption: $1.41 \%$ & \\
\hline & & Fineness modulus: 6.9 & \\
\hline & & Solid content:56.7\% & \\
\hline & \multirow{5}{*}{$\begin{array}{l}\text { M class Recycled } \\
\text { coarse aggregate }\end{array}$} & Absolute dry density:2.45[g/ $\left.\mathrm{cm}^{3}\right]$ & \multirow{5}{*}{ MG } \\
\hline & & Water absorption:2.94\% & \\
\hline & & Fineness modulus:6.6 & \\
\hline & & Solid content:58.2\% & \\
\hline & & Adhesive mortar ratio: $43.4 \%$ & \\
\hline & \multirow{5}{*}{$\begin{array}{l}\text { L class Recycled } \\
\text { coarse aggregate }\end{array}$} & Absolute dry density:2.30[g/ $\left.\mathrm{cm}^{3}\right]$ & \multirow{5}{*}{ LG } \\
\hline & & Water absorption:6.72\% & \\
\hline & & Fineness modulus: 6.5 & \\
\hline & & Solid content:55.1\% & \\
\hline & & Adhesive mortar ratio: $42.38 \%$ & \\
\hline Agent & $\begin{array}{c}\text { Air entraining and } \\
\text { water reducing agent }\end{array}$ & Alkyl ether based anionic surfactant & \\
\hline \multirow{3}{*}{ Admixture } & \multirow{3}{*}{ Fly ash } & Density:2.27[g/cm3] & \multirow{3}{*}{ FA } \\
\hline & & Ignition loss: $1.96 \%$ & \\
\hline & & 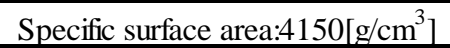 & \\
\hline
\end{tabular}


Table 2 shows the mix proportion used in this study. The water content per unit volume was $180 \mathrm{~kg} / \mathrm{m}^{3}$, the cement content per unit volume was $327 \mathrm{~kg} / \mathrm{m}^{3}$, and the watercement ratio was 55\%. Also, when fly ash was used, it was substituted for fine aggregate. For the creep tests, the strain was measured according to JIS A 1157 ("Compressive Creep Test Method of Concrete"). The test pieces were removed from the molds after 1 day of aging, cured in water at $20^{\circ} \mathrm{C}$ for 7 days, and then cured in a thermostated room prior to the creep tests. As the humidity of the thermostated room was not strictly controlled, it was not possible to conduct the creep tests at constant humidity. For the creep tests, we used a loading device with a separation-type hydraulic jack and installed three test pieces in a vertically stacked configuration. Loading was started at 28 days of age at a loading value of one-third of the compressive strength at that age. We attached three strain gauges to different locations in the center of the test piece, and the average value of the three strain gauges was taken as the total measured strain for the test piece. The average value obtained for the three test pieces was taken as the total strain of the concrete specimen. In addition, to determine the loading value, we prepared test pieces for compressive strength tests using a cylinder of $\varphi 100 \times 200 \mathrm{~mm}$ and measured the compressive strength according to JIS A 1108 ("Compressive Test Method for Concrete"). We cured the test pieces for the compressive strength tests in the thermostated room to conduct the creep tests.

Table 2. Mix proportions

\begin{tabular}{|c|c|c|c|c|c|c|c|c|c|c|c|}
\hline & \multirow{2}{*}{$\begin{array}{c}\mathrm{W} / \mathrm{C} \\
{[\%]} \\
\end{array}$} & \multirow{2}{*}{$\begin{array}{l}\mathrm{W} / \mathrm{B} \\
\%]\end{array}$} & \multicolumn{9}{|c|}{ Unit Content $\left[\mathrm{kg} / \mathrm{m}^{3}\right]$} \\
\hline & & & $\mathrm{W}$ & $\mathrm{C}$ & NS & NG & MS & MG & LS & LG & FA \\
\hline $\mathrm{NN}$ & \multirow{8}{*}{55} & \multirow{4}{*}{55} & \multirow{8}{*}{180} & \multirow{8}{*}{327} & 832 & 945 & 0 & 0 & 0 & 0 & 0 \\
\hline MM & & & & & 0 & 0 & 749 & 870 & 0 & 0 & 0 \\
\hline LL & & & & & 0 & 0 & 0 & 0 & 698 & 885 & 0 \\
\hline $\mathrm{LM}$ & & & & & 0 & 0 & 0 & 870 & 698 & 0 & 0 \\
\hline NN-FA & & \multirow{4}{*}{41} & & & 715 & 945 & 0 & 0 & 0 & 0 & 112 \\
\hline MM-FA & & & & & 0 & 0 & 621 & 917 & 0 & 0 & 112 \\
\hline LL-FA & & & & & 0 & 0 & 0 & 0 & 621 & 841 & 112 \\
\hline LM-FA & & & & & 0 & 0 & 0 & 917 & 579 & 0 & 112 \\
\hline
\end{tabular}




\section{RESULTS AND DISCUSSION}

\section{Compressive Strength}

Figure 1 shows the compressive strength after 28, 56, and 182 days of aging. The compressive strength increased with increasing aging time for all the concrete specimens. Furthermore, the compressive strength decreased with decreasing quality of recycled aggregate. Comparing LL-FA with LM-FA, the values were almost equal. These results confirm that the compressive strength was more strongly influenced by the quality of the fine aggregate than the quality of the coarse aggregate.

\section{Unloaded Strain}

Figure 2 shows the unloaded strain (drying shrinkage). As with the compressive strength, the unloaded strain was found to be affected by the quality of the aggregate. MM-FA exhibited a lower drying shrinkage ratio than the other concrete specimens containing recycled aggregate, which displayed almost the same value as NN-FA. These results demonstrated that the dry shrinkage strain could be expected to be used for the structure of M-class recycled aggregate. Compared with the concrete specimens not containing fly ash, the specimens containing fly ash generally exhibited lower strains. In the concrete specimens containing natural aggregate, the strain reduction rate was small, but in the specimens containing recycled aggregate, the strain was reduced by approximately $200 \mu$. Therefore, owing to the suppression of drying shrinkage by the fly ash and the corresponding decrease in the amount of fine aggregate, the possibility of suppressing the increase in the drying shrinkage ratio of recycled concrete by the addition of fly ash was demonstrated.
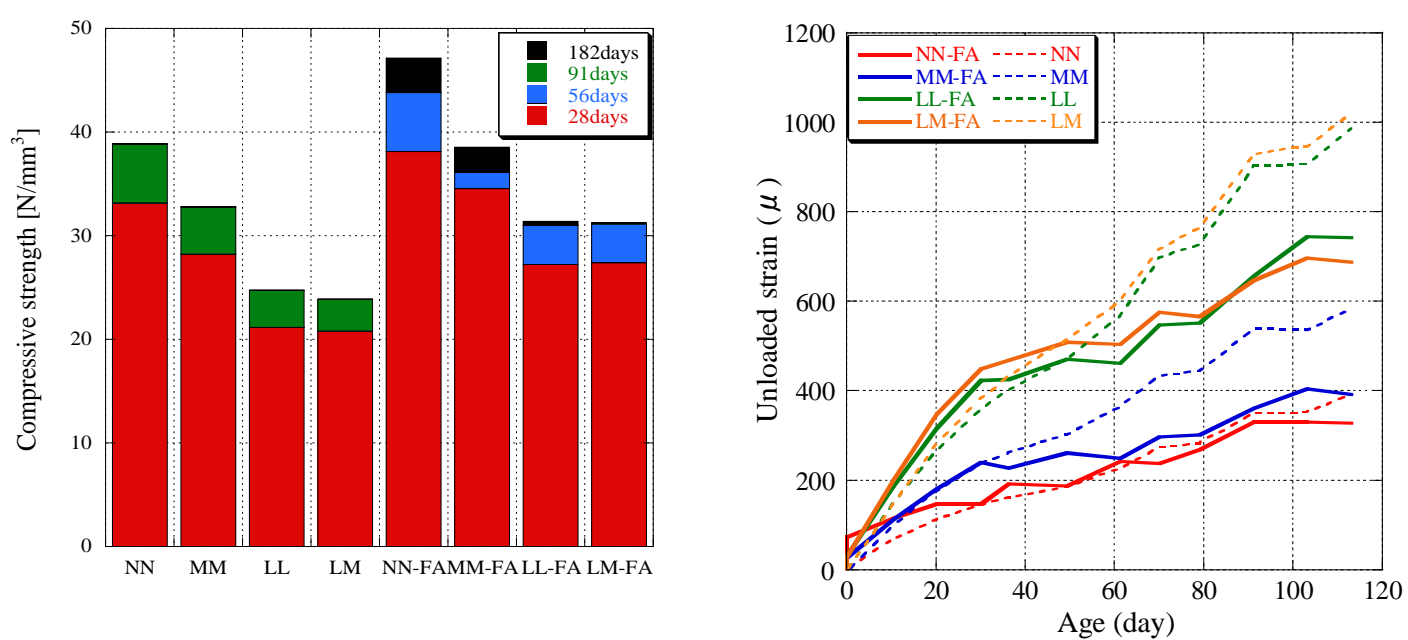
Figure 1. Compressive strength

\section{Compression Creep Properties}

Figure 3 presents the creep strain (excluding elastic strain and unloaded strain from total measured strain). The creep strain showed a tendency to increase with decreasing aggregate quality, and LL-FA exhibited higher strain than LM-FA. In addition, since the creep strain of LM-FA was considerably higher than that of MM-FA, it was confirmed that the quality of the fine aggregate affected the creep strain. The results also demonstrated that the increase of creep strain can be suppressed by the incorporation of fly ash, regardless of the aggregate quality.

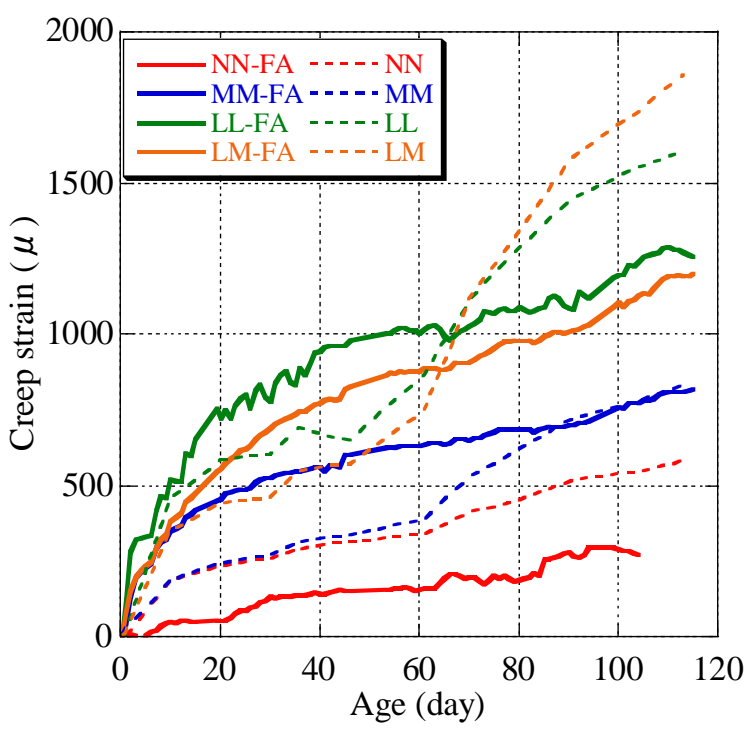

Figure 3. Creep strain

\section{Comparison of Predicted and Measured Values}

We used a prediction formula (AIJ formula ${ }^{4}$ ) developed by the Architectural Institute of Japan that can be used to finely adjust the coefficients for each concrete specimen, and examined the correspondence between the measured and predicted values of creep strain. Equation 1 shows the AIJ formula:

$$
\begin{aligned}
C\left(t, t_{0}\right) & =C R \cdot \log _{e}\left(t-t_{0}+1\right) \ldots \\
C R & =(6.8 \cdot x-0.12 \cdot G+17.5) \cdot\left(t_{0}\right)^{-0.33} \cdot\left(1-\frac{h}{100}\right)^{0.36} \cdot(V / S)^{-0.43}
\end{aligned}
$$

where $C\left(t, t_{0}\right)$ is the specific creep strain $\left(\times 10^{-6} /\left(\mathrm{N} / \mathrm{mm}^{2}\right)\right), C R$ is the coefficient obtained by regression analysis $\left(\times 10^{-6} /\left(\mathrm{N} / \mathrm{mm}^{2}\right)\right), t$ is the aging time (days), $t_{0}$ is the 
age at which loading was started (days), $G$ is the weight of coarse aggregate per unit volume $\left(\mathrm{kg} / \mathrm{m}^{3}\right), h$ is the relative humidity $(\%)$, and $V / S$ is the volume-to-surface-area ratio.

We also numerically evaluated the prediction accuracy based on the RMSE value, which indicates how much the predicted value deviates from the measured value. Figure 4 shows a comparison of the predicted values obtained using the AIJ equation and the measured values. The AIJ formula tended to underestimate the creep strain for the three concrete specimens based on recycled aggregate, but overestimated the creep strain for the NN-FA specimen based on natural aggregate. The overestimation for the NN-FA specimen is considered to originate from the suppression of the creep strain by the fly ash. The RMSE value for MM-FA was 12.80, which was the highest value observed in this study. However, numerical values related to the state and quality of the aggregate are not considered in the AIJ formula, and consequently the predicted value does not account for the influence of the aggregate. In addition, the prediction formula is almost unaffected by admixture; for example, there was almost no difference in the predicted values for the various concrete specimens. Since recycled aggregate and fly ash were used in this study, we examined the use of a correction factor to match the predicted values to the measured values. Figure 5 shows the measured values for each concrete specimen, the predicted values obtained using the AIJ equation, and the predicted values after correction. It seems that there was no consistency in the predicted values owing to the influence of the humidity of the thermostated chamber, which was not constant. The correction factors (RMSE values) for NN-FA, MM-FA, LL-FA, and LM-FA were 0.34 (3.03), 1.27 (6.25), 2.44 (13.23), and 2.24 (11.37), respectively.

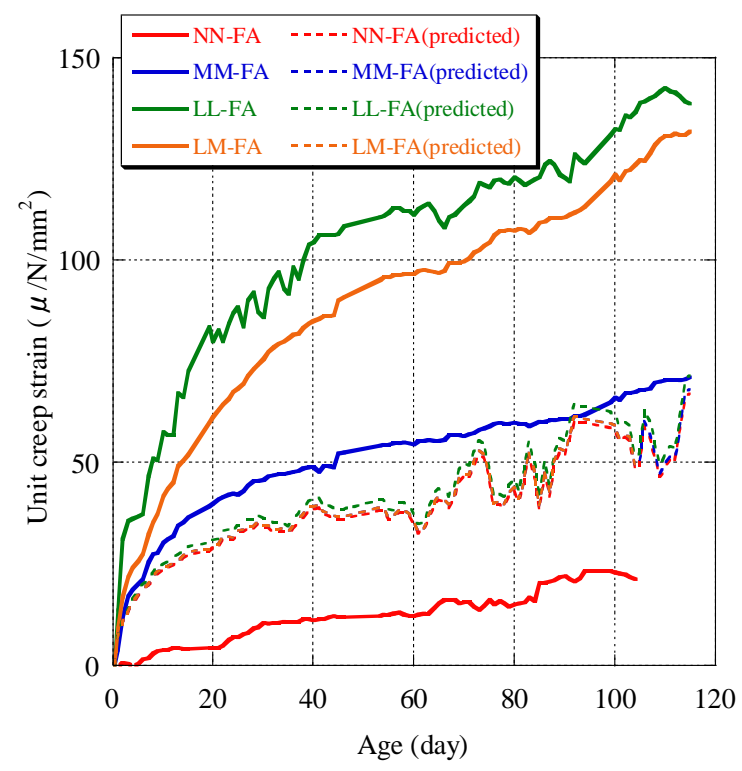


Figure 4. Predicted values and measured values

To use the AIJ formula to accurately predict the creep strain of recycled aggregate concrete containing fly ash, we considered the possibility of using not only the correction coefficient for recycled concrete but also an additional correction coefficient. Figure 6 shows the experimentally measured values for each of the concrete specimens not containing fly ash, the predicted values obtained using the AIJ equation, and the predicted values after correction. Compared with the concrete specimens without fly ash, the value of the correction coefficient decreased. In addition, in the concrete specimens containing fly ash, the RMSE value decreased and the goodness of fit after applying the correction coefficient increased. These results demonstrate that the goodness of fit of the predicted creep strains could be improved by including the additional correction coefficient in the AIJ formula to reflect the suppression of the creep strain of recycled concrete by the incorporation of fly ash.

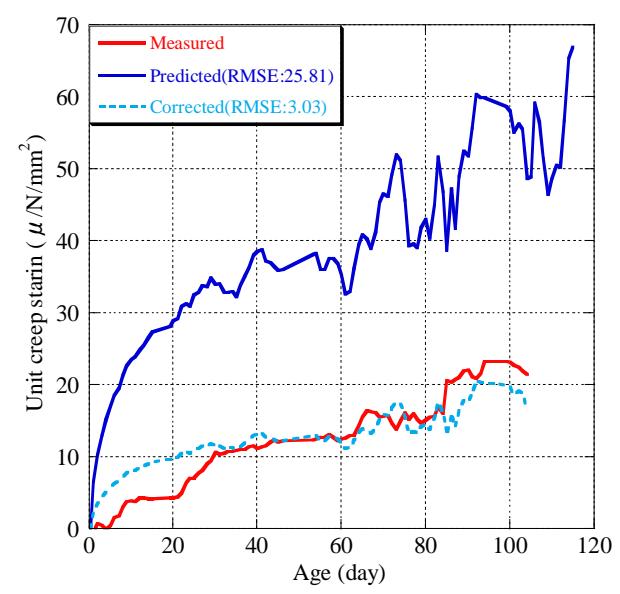

NN-FA

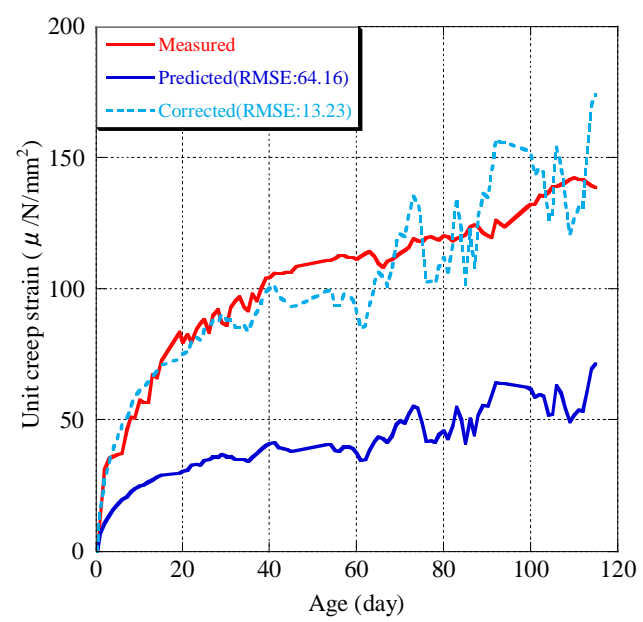

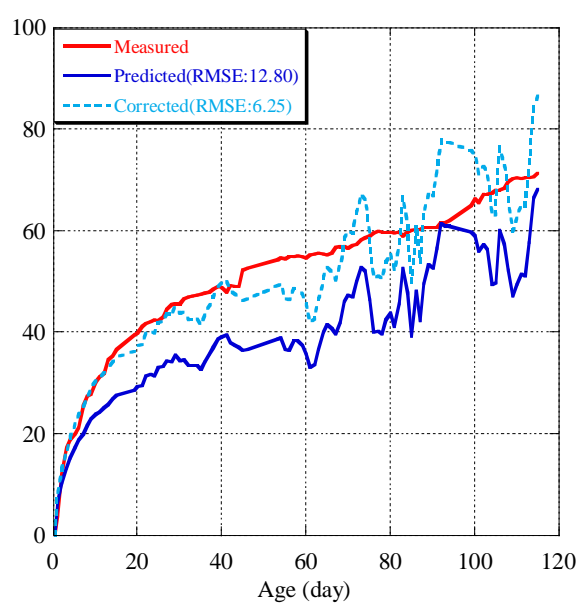

MM-FA

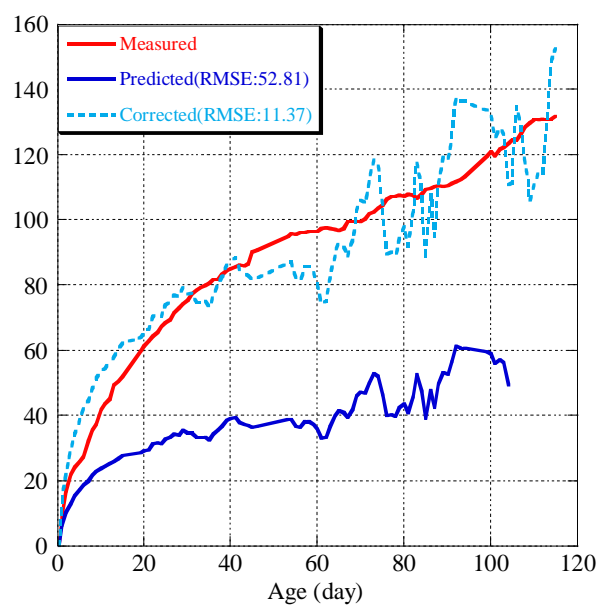


Figure 5. Measured values and predicted values after correction
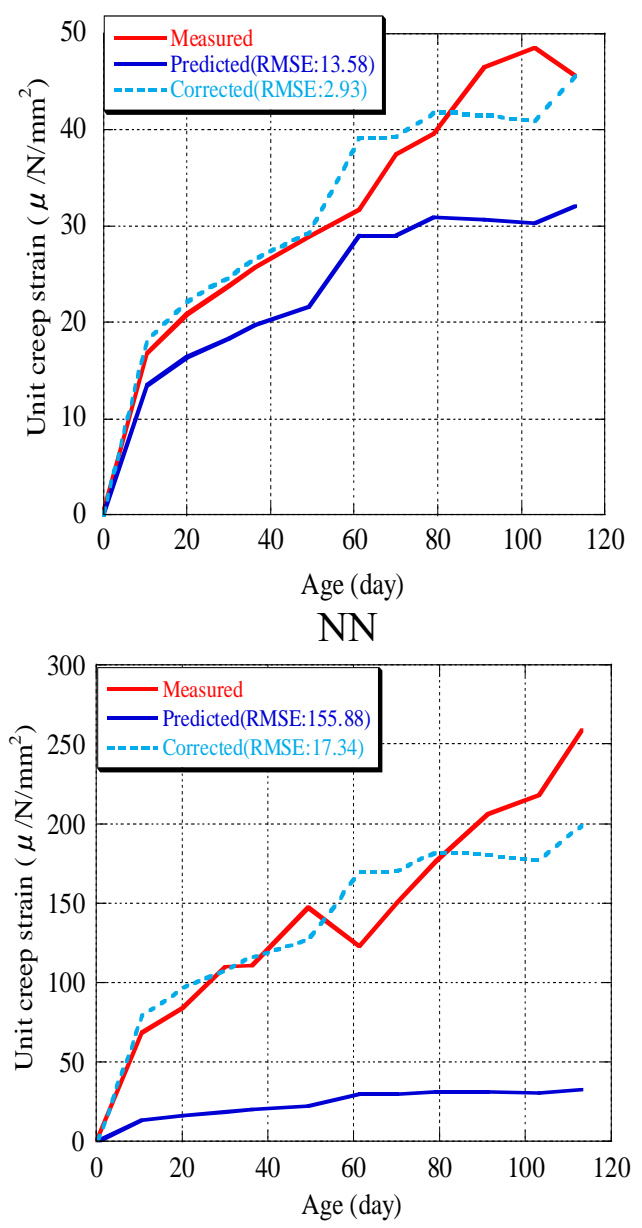

LL

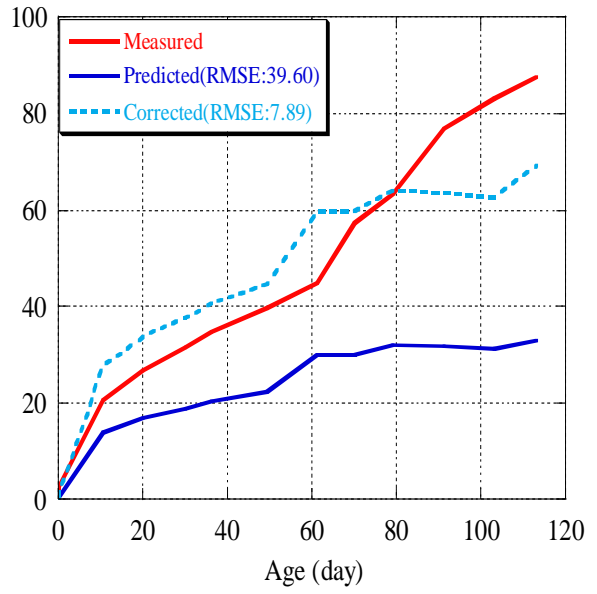

MM

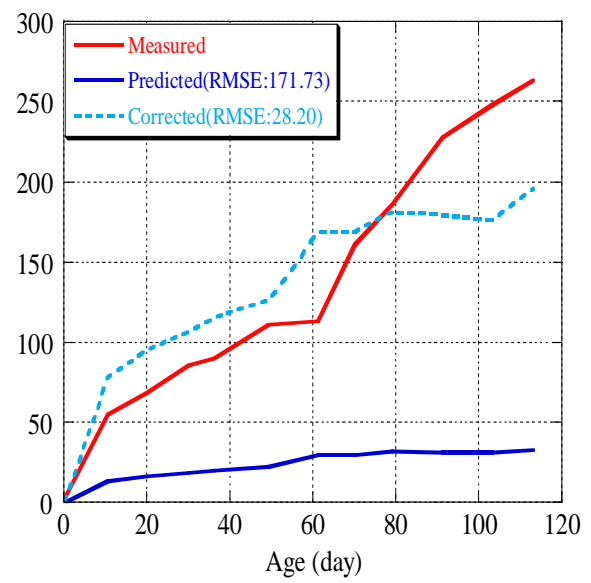

LM

Figure 6. Measured values and predicted values after correction

(no containing fly ash)

\section{Correction Coefficient and Physical Parameters}

Although the possibility of improving the prediction accuracy using the correction coefficient has been demonstrated, the physical origin of this correction coefficient was not readily apparent. In this section, we focus on the physical properties of the materials and investigate the relationship between the correction coefficient and the physical parameters using single regression analysis. Table 3 shows the correlation 
between the correction coefficient and each physical parameter for the fine and coarse aggregates. For the fine aggregates, a strong correlation was observed between the physical parameters, except for the fineness modulus, and the correction coefficient. For the coarse aggregates, a strong correlation was observed between the physical parameters, except for the solid content and the adhesive mortar ratio, and the correction coefficient. A simple regression analysis was performed focusing on the five physical parameters examined, namely, water absorption, absolute dry density, fineness modulus, solid content, and adhesive mortar ratio.

Table 3. Correlation between the correction coefficient and each physical property value (i) Fine aggregate

\begin{tabular}{c|c|c|c|c|c|c}
\hline & $\begin{array}{c}\text { Correction } \\
\text { coefficient }\end{array}$ & $\begin{array}{c}\text { Water } \\
\text { absorption }\end{array}$ & $\begin{array}{c}\text { Absolute } \\
\text { dry density }\end{array}$ & $\begin{array}{c}\text { Fineness } \\
\text { modulus }\end{array}$ & $\begin{array}{c}\text { Solid } \\
\text { content }\end{array}$ & $\begin{array}{c}\text { Adhesive } \\
\text { mortar ratio }\end{array}$ \\
\hline \hline Correction coefficient & 1.000 & & & & & \\
\hline Water absorption & 0.996 & 1.000 & & & & \\
\hline Absolute dry density & -0.994 & -0.996 & 1.000 & & & \\
\hline Fineness modulus & -0.661 & -0.679 & 0.608 & 1.000 & & \\
\hline Solid content & -0.991 & -0.993 & 1.000 & 0.584 & 1.000 & \\
\hline Adhesive mortar ratio & 0.996 & 0.998 & -0.999 & -0.636 & -0.998 & 1.000 \\
\hline
\end{tabular}

(ii)Coarse aggregate

\begin{tabular}{c|c|c|c|c|c|c}
\hline & $\begin{array}{c}\text { Correction } \\
\text { coefficient }\end{array}$ & $\begin{array}{c}\text { Water } \\
\text { absorption }\end{array}$ & $\begin{array}{c}\text { Absolute } \\
\text { dry density }\end{array}$ & $\begin{array}{c}\text { Fineness } \\
\text { modulus }\end{array}$ & $\begin{array}{c}\text { Solid } \\
\text { content }\end{array}$ & $\begin{array}{c}\text { Adhesive } \\
\text { mortar ratio }\end{array}$ \\
\hline Correction coefficient & 1.000 & & & & & \\
\hline Water absorption & 0.982 & 1.000 & & & & \\
\hline Absolute dry density & -0.984 & -0.947 & 1.000 & & & \\
\hline Fineness modulus & -0.952 & -0.892 & 0.990 & 1.000 & & \\
\hline Solid content & -0.673 & -0.791 & 0.553 & 0.429 & 1.000 & \\
\hline Adhesive mortar ratio & 0.701 & 0.743 & -0.753 & -0.732 & -0.495 & 1.000 \\
\hline
\end{tabular}

Table 4 shows the results of the single regression analysis between each physical parameter and the correction coefficient. For the fine aggregates, the $p$ values for all of the physical parameters except for the fineness modulus were lower than the significance level of 5\% (0.05). For the coarse aggregates, the $p$ values for all of the physical parameters except for the solid content and adhesion mortar ratio were lower 
than the significance level of 5\%. With respect to the fine aggregates, extremely high coefficients of determination $\left(R^{2}\right)$ were observed except for the fineness modulus, and it was therefore considered that the four physical parameters except for the fineness modulus could explain the correction coefficient. Based on these results, the single regression analyses between the correction coefficient and the physical parameters for the fine aggregates are presented in Equations 2-5.

Water absorption: $r_{1 a}=0.17 A+0.23$

Absolute dry density: $r_{1 \rho}=-3.48 \rho+9.31$

Solid content: $r_{1 s}=-0.23 S+14.50$

Adhesive mortar ratio: $\gamma_{1 M}=0.05 M+0.31$

Table 4. Single regression analysis of each physical parameter and the correction coefficient

(i)Fine aggregate

\begin{tabular}{c|c|c|c|c}
\hline Objective variable & Explanation & $t$ & $P$-value & $\begin{array}{c}\text { Determination } \\
\text { coefficient } R^{2}\end{array}$ \\
\hline \hline \multirow{4}{*}{ Correction coefficient } & Water absorption & 16.20 & 0.003 & 0.99 \\
\cline { 2 - 5 } & Absolute dry density & -12.73 & 0.006 & 0.98 \\
\cline { 2 - 5 } & Fineness modulus & -1.24 & 0.330 & 0.44 \\
\cline { 2 - 5 } & Solid content & -10.65 & 0.008 & 0.98 \\
\cline { 2 - 5 } & Adhesive mortar ratio & 15.37 & 0.004 & 0.99 \\
\hline
\end{tabular}

(ii)Coarse aggregate

\begin{tabular}{c|c|c|c|c}
\hline Objective variable & Explanation & $t$ & $P$-value & $\begin{array}{c}\text { Determination } \\
\text { coefficient } R^{2}\end{array}$ \\
\hline \hline \multirow{5}{*}{ Correction coefficient } & Water absorption & 7.33 & 0.018 & 0.96 \\
\cline { 2 - 5 } & Absolute dry density & -7.89 & 0.015 & 0.97 \\
\cline { 2 - 5 } & Fineness modulus & -4.41 & 0.047 & 0.91 \\
\cline { 2 - 5 } & Solid content & -1.29 & 0.320 & 0.45 \\
\cline { 2 - 5 } & Adhesive mortar ratio & 1.39 & 0.300 & 0.49 \\
\hline
\end{tabular}

With respect to the coarse aggregates, extremely high coefficients of determination were again observed except for the solid content and adhesive mortar rate, and it was therefore considered that the three physical property values except for the solid content and adhesive mortar rate could explain the correction coefficient. Based on these results, the single regression analyses between the correction coefficient and the 
physical parameters for the coarse aggregates are presented in Equations 6-8.

Water absorption: $r_{2 a}=0.35 A+0.01$

Absolute dry density: $r_{2 \rho}=-5.17 \rho+14.17$

fineness modulus: $r_{2 F}=-4.87 F+33.81$

Furthermore, since the $t$-values for the water absorption and adhesive mortar ratio were positive, the correction coefficient and the predicted creep strain increase as the value of the physical parameter increases. Conversely, since the t-values for the absolute dry density, fineness modulus, and solid content were negative, the correction coefficient and the predicted creep strain decrease as the value of the physical parameter increases.

Comparing the results for the coarse and fine aggregates, the highest coefficients of determination were observed for the water absorption and adhesive mortar ratio of the fine aggregates. Since recycled aggregates were used in the specimens examined in this study (except for NN-FA), it was considered that the correction coefficient was largely influenced by water absorption.

\section{CONCLUSION}

(1) It was confirmed that the unloaded strain and creep strain of recycled concrete are greatly influenced by the quality of the fine aggregate, as reported in previous studies. Furthermore, the incorporation of fly ash suppressed the unloaded strain and creep strain of the recycled concrete.

(2) The AIJ formula tended to underestimate the creep strain for concrete containing recycled aggregate and overestimate the creep strain for concrete containing natural aggregate. By applying correction coefficients, it was possible to increase the goodness of fit of the predicted creep strains.

(3) Single regression analysis confirmed that the correction coefficient proposed in this study was most strongly influenced by the water absorption and adhesive mortar ratio of the fine aggregates.

\section{REFERENCES}

1) Keiichi Imamoto et al: A study on Creep / Drying Shrinkage Characteristics of 
Recycled Concrete, Report of Concrete Engineering Annual Papers Report, vol.19, No.1, 1997

2) Ayano Toshiki: Present state of creep prediction method and its accuracy Vol. 43, No. 5, 2005.5

3) Japan Concrete Engineering Association: Symposium on Promotion of Recycled Aggregate for Concrete, pp 102 - 170, Japan Concrete Engineering Association (2005)

4) Yoshiaki Sato et al: A study on prediction equation of time dependence of concrete based on domestic experimental data, Journal of Architectural Institute of Japan, p.599, 9-15, 2006 